\title{
Experience of Artificial Intelligence Implementation in Japan
}

\author{
Loudmila Belova ${ }^{1, *}$ \\ ${ }^{1}$ Lomonosov Moscow State University 46, Leninskie Gory, Moscow, 119991, Russian Federation
}

\begin{abstract}
The main purpose of this article is to identify the essence of artificial intelligence (AI), to determine its impact on various aspects of life and to specify the knowledge gained by studying the directions of AI application in one of the most advanced countries - Japan, the world leader in robotics. Main conclusions from the study: important characteristics of the modern approach to the AI phenomenon are: first, the human pattern that once guided and motivated AI research has largely been pushed out of sight; second, this is why certain views on what we should know and do with intelligent machines are gradually emerging; third, there is a growing need to combine the efforts of research institutes in different countries in studying the theoretical aspects of AI. Japan has very good prospects for establishing and developing bilateral AI cooperation with Russia and Kazakhstan.
\end{abstract}

\section{Introduction}

Artificial intelligence (AI) is transforming every aspect of our lives. It influences how we work and play. It promises to help solve global challenges like climate change and access to quality medical care. AI has a major impact on the economy and society. Therefore, governments, international organizations, corporations and scientists have a wide range of initiatives aimed at studying various aspects of AI. The purpose of the article is to show what is new at the present stage of AI and to identify areas of use of artificial intelligence in one of the most advanced economies - Japan.

\footnotetext{
* Corresponding author: lgbelova@bk.ru
} 


\section{Methodology and Data}

The author's research methodology includes general scientific principles of cognition of economic phenomena - dialectical, concrete historical, systemic and other approaches, and general scientific methods of systemic, logical, structural, factorial and comparative analysis. The information-theoretical basis of the research was the fundamental concepts of domestic and foreign scientists, materials of international organizations, information and analytical materials of national research institutions.

\section{Results and Discussion}

\subsection{Applications of new technologies}

Modern society, created in the most developed countries, is called a "post-informational society", an "omnipresent society". In accordance with the concept of the ubiquitous society, the development paradigms of Japan, for example, were replaced as follows: industrial society (1980-1990); the information society (1991-2000); transition to the postinformational society (2001-2004); transition to the digital society (Society 5.0, currently).

Technological basis of the current stage of development of the world economy is information technology (IT), which is a product of innovation, developed through innovation and, in turn, provides the necessary technical capabilities for the implementation of inventions and the introduction of innovations.

The current stage of digital transformation, since 2010 , is characterized by the following aspects:

- turning innovation into an independent source of added value;

- the key role of information and forming the information market;

- increasing in the share of goods that do not have a material shell;

- the creation of technological platforms that bring together supply and demand, production, development, marketing and sales.

Applications of new technologies, including artificial intelligence, in financial services, for example, are presented in Table 1.

Tab. 1 Applications of new technologies to financial services

\begin{tabular}{|c|c|c|c|c|c|c|c|c|}
\hline \multirow[b]{2}{*}{$\begin{array}{l}\text { DIGITAL } \\
\text { TECHNOLOG } \\
\mathrm{Y}\end{array}$} & \multicolumn{8}{|c|}{ FINANCIAL ACTIVITIES AND SERVICES } \\
\hline & $\begin{array}{l}\text { Payment } \\
\text { services }\end{array}$ & $\begin{array}{c}\text { Advisory } \\
\& \\
\text { agency } \\
\text { services } \\
\text { Planning }\end{array}$ & $\begin{array}{c}\text { Investment } \\
\& \\
\text { trading }\end{array}$ & $\begin{array}{c}\text { Lending } \\
\& \\
\text { funding }\end{array}$ & $\begin{array}{l}\text { Insuranc } \\
e\end{array}$ & Security & Operations & $\begin{array}{l}\text { Communi } \\
\text { cations }\end{array}$ \\
\hline $\begin{array}{l}\text { Distributed } \\
\text { ledger } \\
\text { technology }\end{array}$ & $\mathrm{x}$ & $\mathrm{x}$ & $\mathrm{x}$ & $\mathrm{x}$ & $\mathrm{x}$ & $\mathrm{x}$ & $\mathrm{x}$ & $\mathrm{x}$ \\
\hline Big Data & $\mathrm{x}$ & $\mathrm{x}$ & $\mathrm{x}$ & $\mathrm{x}$ & $\mathrm{x}$ & $\mathrm{x}$ & $\mathrm{x}$ & \\
\hline $\begin{array}{l}\text { Internet of } \\
\text { things }\end{array}$ & $\mathrm{x}$ & $\mathrm{x}$ & & & & & & \\
\hline Cloud & $\mathrm{x}$ & $\mathrm{x}$ & & & & & & \\
\hline
\end{tabular}




\begin{tabular}{|l|l|l|l|l|l|l|l|l|}
\hline computing & & & & & & & & \\
\hline $\begin{array}{l}\text { Artificial } \\
\text { intelligence }\end{array}$ & $\mathrm{x}$ & $\mathrm{x}$ & $\mathrm{x}$ & $\mathrm{x}$ & & & \\
\hline $\begin{array}{l}\text { Biometric } \\
\text { technology }\end{array}$ & $\mathrm{x}$ & $\mathrm{x}$ & & & & & & \\
\hline $\begin{array}{l}\text { Augmented / } \\
\begin{array}{l}\text { Virtual } \\
\text { reality }\end{array}\end{array}$ & $\mathrm{x}$ & $\mathrm{x}$ & $\mathrm{x}$ & & & & & \\
\hline
\end{tabular}

Source: [1]

The potential impact of digital technologies (DTS) and artificial intelligence (AI) on the labor market is limitless. AI has a particularly large impact on the global labor market. There are three levels of AI development: (1) auxiliary intelligence, which is widely used now (for example, the GPS navigation program); (2) advanced intelligence, which is spreading more and more actively, helping people and organizations to perform tasks that they can not do on their own (for example, the system of joint taxi rides could not exist without a combination of programs that ensure its operation); (3) autonomous intelligence the technology of the future, involving the use of machines that will act independently (for example, drones) [2].

\subsection{Theoretical aspects of the concept of "artificial intelligence"}

Artificial intelligence (AI) is defined differently. The most common definitions are as follows (to save time, I'll just show these definitions on a slide):

- scientific direction within which the problems of hardware or software modeling of those types of human activity which are traditionally considered intellectual are set and solved;

- the property of intelligent systems to perform functions (creative), which are traditionally considered the prerogative of man;

- it is the science and engineering of making intelligent machines, especially intelligent computer programs; it is related to the similar task of using computers to understand human intelligence, but AI does not have to confine itself to methods that are biologically observable [3].

The first use of the term "artificial intelligence" for scientific purposes occurred in the summer of 1956 during the implementation at Dartmouth Summer Research Project on Artificial Intelligence under the leadership of John McCarthy, Marvin L. Minsky, Nathaniel Rochester and Claude Shannon [4].

Early attempts at automation under the so-called Dartmouth symbolic approach, focused on human intelligence, which was the Central model. The goal was to reproduce intelligent human behavior in machines by uncovering the processes at work in human intelligence such that they could be automated.

However, during the 20th century, most of the approaches of early AI researchers were changed. Modern approaches are deliberately designed to bypass "human" behavior. The slides present the essence of these approaches. Look at the slides.

The first modern approach was formulated by Luciano Floridi: most researchers want to design automated systems that perform well in complex problem domains by any means, rather than by human-like means [5].

The second modern approach is described by Edward Feigenbaum, the Stanford-based computer scientist who gave the name to the field of AI, now called "expert systems": the 
power of problem solving, manifested in the work of an intelligent agent, is primarily a consequence of the knowledge of the specialist used by the agent [6].

Proponents of the third approach are the developers of automated pattern recognition, focused on attempts to artificially reproduce the synapses of the brain in 'artificial neural networks' [7].

The historical perspective involves the revision of the concept of artificial intelligence. Modern concept of AI includes the latest achievements in the field of machine learning, artificial neural networks and robots.

\subsection{Financing the introduction of artificial intelligence in foreign countries}

The Organisation for Economic co-operation and Development (OECD) is analysing the economic and social impacts of AI technologies to identify good practices for public policy.

Investment funds, venture capital firms and corporate investors are stepping up investments in artificial intelligence startups, reflecting a growing global interest in AI technologies and their commercial applications.

According to OECD, there has been a significant increase in investment in Artificial Intelligence start-ups (AI start-ups).

After five years of steady growth, private equity investment in AI has accelerated since 2016, with the amount of private equity invested doubling from 2016 to 2017 (Figure 1).

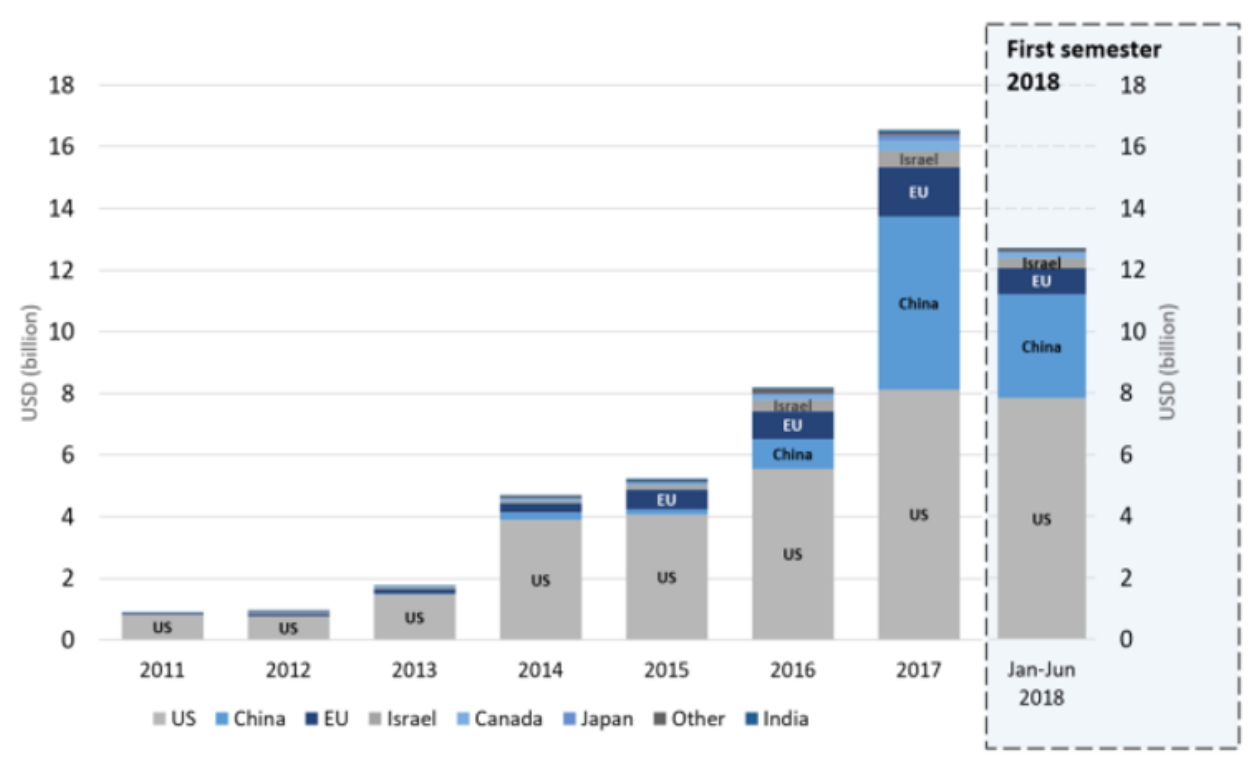

Figure 1-Total amount of private investments in AI startups, 2011-2017 and in the first half of 2018

Source: [8].

In total, more than USD 50 billion was invested in AI start-ups during the period 2011 through to mid-2018. The surge in private investment suggests that investors are 
increasingly aware of the potential of AI, and are crafting their investment strategies accordingly.

New analysis by the OECD found that AI start-ups have so far attracted around $12 \%$ of all worldwide private equity investments in the first half of 2018, a steep increase from just $3 \%$ in 2011 [8].

Data suggest that start-ups operating in the United States (US) account for the majority of AI start-up equity investments worldwide, both in the number of investment transaction ("deals") and in US dollars invested, accounting for two-thirds of the total value of investment since 2011 (Figure 1).

The People's Republic of China has seen a dramatic upsurge in AI start-up investment since 2016 and now appears to be the second player globally in terms of the value of AI equity investments received. From just $3 \%$ in 2015, Chinese companies attracted $36 \%$ of global AI private equity investment in 2017 and an annual average of $21 \%$ over the period from 2011 through mid-2018. This growth reflects the efforts of the Chinese government and the Chinese tech sector to lead in the field of AI [8].

According to the American consulting company Global Market Insights, Artificial Intelligence Market size is expected to a have significant growth over the forecast timeline. Increasing complex IT databases and rising AI applications in numerous applications will drive the artificial intelligence market growth. Increasing $R \& D$ in human-like robots and the rising deployment rate in the various regions are likely to fuel the artificial intelligence market growth. The growing adoption of artificial intelligence-enabled software and products to improve customer services is further augmenting the demand. The requirement for such technologies in various sectors, such as healthcare, transportation, retail, and manufacturing, is extensively contributing to the industry growth. The artificial intelligence market is segmented by technology into robotics, digital personal assistance, querying method, deep learning context aware processing, and natural language processing. Robotics and natural language processing are the major contributing segments in the artificial intelligence market. The increasing implementation of natural language processing in the retail sector for the enhancement of customer services is a major factor that improves the segment growth. Additionally, the natural language processing implementation in different AI applications, such as smartphones, robots, and car infotainment, will further drive the industry growth. Moreover, robotic applications for the industrial automation and several government initiatives for smart manufacturing will further fuel the market growth. On the basis of application, the artificial intelligence market is segmented into retail, transportation $\&$ automotive, oil \& gas, media \& advertising, manufacturing, healthcare, BFSI, and agriculture. Transportation \& automotive is projected to hold the largest market share in the application segment followed by healthcare and media \& advertising services. Rising adoption of AI in car infotainment and atomization will drive the segment growth over the forecast timeline. Based on offerings, the artificial intelligence market is classified into products and services. The product segment including software and hardware held a substantial market share in 2016. The extensive development in AI-enabled hardware and software products are the major factors boosting the industry growth [9].

\subsection{Artificial intelligence in Japan}

Japanese artificial intelligence research began thirty years late. A big problem in this area is also the lack of personnel. To make up for the lag behind the advanced countries in the field of AI, a large number of AI studies are currently being conducted in Japan. 
National Institute of Advanced Industrial Science and Technology (AIST) is the largest scientific and research center in the field of artificial intelligence in Japan.

AI development is recognized as a national necessity in Japan:

- first, the hard work of the Japanese is so high that it forced the government to adopt in 2014 a special law on measures to prevent death from overwork - White Paper on Measures to Prevent Karoshi [10], and AI can replace part of the human effort;

- secondly, the forecasts of market development; so, according to the American consulting company Global Market Insights, the average annual growth of the AI technology market in 2018 was $20 \%$, it is expected that by 2024 the value of this market will be $\$ 24$ billion [9].

Development efforts are bearing fruit. Several examples can be cited. As I said, nowadays AI concept includes the latest advances in machine learning, neural networks and robots. Start with robots.

Personal assistant for office workers. There was a whole direction of artificial intelligence systems - Robotic Process Automation (RPA), aimed at the complete replacement of the employee with a digital robot. RPA enables the automation of a wide range of human handled tasks by leveraging cognitive tools such as AI and machine learning. RPA, also called "Digital Labor", enables the automation of a wide range of human handled tasks by leveraging cognitive tools such as AI and machine learning. The automation of a large portion of tasks which have until now been considered to be manageable only by humans. For example, Digital Labor can be utilized to perform an expense report check quickly and with complete accuracy, normally a time consuming process for a finance department. Robots can learn human-handled procedures and automate a broad range of tasks. The current business climate includes workforce shortages, caused by decreasing birthrates and an aging population, in addition to the government's promotion of work-life balance. Because of these reasons, workplace efficiency is vital to maintain their sustainable growth, now more than ever. By automating time consuming tasks, employees are able to use their time more efficiently and are allowed to focus on higher level tasks [11].

Employees of the Hitachi Center for technological innovation have developed a robot assistant to minimize the time that office workers spend on their non-core work. The robot assistant can completely replace the office manager who prepares business trips for other employees. The slide shows the advantages of Robotic Process Automation.

The robot is motivating to clean your desktop. Japan is world's leading manufacturer and consumer of robots. About half of the world's robot are made and used in Japan. About half of the world's 4,500 robot engineers are in Japan. Robots have been developed in Japan to help build products, to provide useful services and entertainment for people and to provide companionship for them. Research is taking place at corporations such as Sony, Honda and NEC and universities, most notably Waseda University's famed robotics lab in Tokyo. In Japan there are dancing robots, car-driving robots, stair-climbing robots, a pair of courting robots, robot families and their neighbors. One Tokyo department store has sold piano-playing home robots for $\$ 42,000$ a piece. In the future it is hoped that robots will fight fires and guide the blind [12].

According to World Robotics - Industrial Robot Report 2018, recently published by the International Federation of Robotics, Japan is the world's leading supplier of industrial robots. Japanese industrial robot manufacturers delivered just over half (almost 55\%) of industrial robots supplied in 2017 - 39\% more than in 2016. Japan is not only a leading manufacturer and exporter of robots, it is also a leading robot adopter. With 297,200 industrial robots at work in Japan in 2017, Japan had the second highest installed base of industrial robots in 2017 (after China with 473,400 units) [13]. 
As scientists from the Tohoku University and the Iwate University believe, performance is reduced if there are other items except documents, laptop and stationery on the table. Scientists implemented the experiment with the mobile robot Moway, similar to a computer mouse. There is stationery on the desktop also: markers, scissors, glue, ruler, pens and pencils. The slides show how the experiment went.

At the beginning of the experiment, a person sits down at the table and five minutes later goes out, for example, for coffee. At this point, the robot analyzes what items are scattered on the table, and throws them on the floor. After that, the robot returns to the starting point.

Forecast "when, where, what" for a comfortable life in big cities. Another area of application of artificial intelligence is the prediction of events based on spatio-temporal analysis of the data array in real time. Numerous powerful point process models have been developed to understand temporal patterns in sequential data from fields such as healthcare, electronic commerce, social networks, and natural disaster forecasting. During the past decades, researchers have made substantial progress in computer vision algorithms that can automatically detect and recognize actions in video sequences [14].

Predicting pedestrian density. Robots are increasingly used in everyday life. As more robots are introduced into human surroundings, it becomes imperative to develop reliable and safe humanrobot interaction. The robots should be able to successfully navigate in a dynamic environment with multiple moving humans to reach their goal positions. In order to develop such systems, the robots should have a good understanding of its environment and the ability to sense, track, and predict the position of all moving humans in its workspace to perform collision-free navigation [15].

Mobile networks in Osaka and Tokyo have become data sources for predicting pedestrian density. Artificial intelligence systems can be trained on streaming data, which increases the reliability of predictions. Such systems can be used to build models of optimal evacuation routes in emergency situations or, for example, in stadiums.

Waste management. Another important topic for the Japanese is waste management. In automatic mode, you can determine what kind of waste (combustible, incombustible, paper, glass, plastic) was collected on a particular day and what was their weight at each collection point. On the basis of these data there is an optimization of routes, planning of loading of incinerators, forecasting of dynamics of growth or decrease in waste in the future at growth or reduction of population. A group of Japanese scientists at Cambridge University is working on this topic. The first object to study were garbage trucks of the Japanese city of Fujisawa. Each such car has sensors of air pollution, noise level, temperature, humidity, solar radiation, GPS-tracker, microphone. With the help of such equipment, scientists receive information about the level of environmental stress in different parts of the city, which are used to predict the environmental situation.

Shoplifting combat. In Japan, artificial intelligence began to be used to combat shoplifting. The AI system analyzes the behavior of each visitor and reports suspicious persons to the seller.

Vaak, a Japanese startup, has developed artificial intelligence software that hunts for potential shoplifters, using footage from security cameras for fidgeting, restlessness and other potentially suspicious body language. While AI is usually envisioned as a smart personal assistant or self-driving car, it turns out the technology is pretty good at spotting nefarious behavior. Like a scene out of the movie "Minority Report," algorithms analyze security camera footage and alert staff about potential thieves via a smartphone app. The goal is prevention: If the target is approached and asked if they need help, there's a good chance the theft never happens. Vaak made headlines in 2018 when it helped to nab a 
shoplifter at a convenience store in Yokohama. The company had set up its software in the shop as a test case, which picked up on previously undetected shoplifting activity. The perpetrator was arrested a few days later. Founded in 2017, Vaak is currently testing in a few dozen stores in the Tokyo area. The company began selling a market-ready version of its shoplifting-detection software this month, and is aiming to be in 100,000 stores across Japan in three years. It has $¥ 50$ million in funding from SoftBank Group Corp.’s AI fund, and is in the middle of its series A round, seeking to raise $¥ 1$ billion [16].

AI to cope with the shortage of doctors. The Japanese government is teaming up with businesses and academia to set up hospitals enhanced by artificial intelligence, seeking to allow short-handed doctors to spend more time on patient care while curbing medical spending. The government is expected to invest more than $\$ 100$ million in the effort over half a decade, with a target of establishing 10 model hospitals by the end of fiscal 2022. AI will help with tasks from updating patients' charts to analyzing tests and parsing images to help with diagnoses. The effort aims to address structural challenges to health care, including the chronic lack of doctors and nurses in some areas and rising medical expenses. The initiative will also help make Japan more competitive on the world stage, giving AI development a shot in the arm and helping boost exports of medical equipment. Three ministries central to the effort -- the education, industry and health ministries -- will recruit participating companies and hospitals this month, targeting AI specialists and medical equipment makers. A basic working framework will be established as early as September, with initial efforts set to focus on cancer patients. Participants will develop AIassisted programs that will automatically enter information into patients' medical records based on their conversations with doctors during examinations. That is expected to free doctors to focus on patients and give more time for discussing their conditions [17].

Developments in the AI segment have Japanese companies Hitachi and Canon, which develop AI to analyze the results of computed tomography.

Artificial intelligence systems in school education. The Japanese authorities intend to introduce artificial intelligence systems in school education. AI will collect data on the performance of students of different ages, analyze the data and determine the strengths and weaknesses of students. On this basis, individual programs will be developed for each student.

Artificial Intelligence is to fix Japan's rigid education system. Daisuke Inada, founder and CEO of Atama+, left a promising career at Mitsui to start an EdTech company he believes will change the way children learn. Daisuke's vision is not the standard EdTech dream of online classes and automated learning. It's one where human instructors are still very much involved and critical to the success of both the students and the programs. Of course, their role will change and the overall structure will look quite different from what we know today [18].

\section{Conclusions}

Digitalization is shaping the global labor market. The future of work is the biggest question of our century. What influence will the continuing march of technology, automation and artifcial intelligence (AI) have on where we work and how we work. This is less about technological innovation and more about the manner in which humans decide to 
use that technology. The shape that the workforce of the future takes will be the result of complex, changing and competing forces.

Summing up the above regarding artificial intelligence (AI), it should be noted that:

- there is no single generally accepted definition and approach to artificial intelligence has been developed from the 1950s to the present day;

- important characteristics of the modern approach to the AI phenomenon are:

- $\quad$ first, the human pattern that once guided and motivated AI research has largely been pushed out of the field;

- $\quad$ second, this is why certain views are gradually emerging on what we should know and do with intelligent machines;

- third, there is a growing need to combine the efforts of research institutes in different countries in the study of theoretical aspects of AI.

Japan has very good prospects for establishing and developing bilateral cooperation in the AI field with Russia and Kazakhstan.

\section{References}

1. Digitalisation and Finance. Financial Markets, Insurance and Pensions. OECD, 2018, p. 14. URL: https://www.oecd.org/finance/private-pensions/Financialmarkets-insurance-pensions-digitalisation-and-finance.pdf

2. Workforce of the future. The competing forces shaping 2030. P. 9. (2019). URL: https://www.pwc.com/gx/en/services/people-organisation/workforce-of-thefuture/workforce-of-the-future-the-competing-forces-shaping-2030-pwc.pdf.

3. J. McCarthy What is Artificial Intelligence? Stanford University / Computer Science Department / Revised November 12, (2007). — URL: http://wwwformal.stanford.edu/jmc/whatisai/; formal.stanford.edu/jmc/whatisai/node1.html

http://www-

4. S. Dick. Artificial Intelligence. Jun 23. (2019). DOI 10.1162/99608f92.92fe150c. URL: https://hdsr.mitpress.mit.edu/pub/0aytgrau

5. L. Floridi. The 4th revolution: how the info sphere is reshaping human reality. Oxford: Oxford University Press. (2016).

6. E. Feigenbaum. The Art of Artificial Intelligence: Themes and Case Studies of Knowledge Engineering. Stanford Heuristics Programming Project Memo HPP-7725, p. 3. (1977).

7. M. Jones. How We Became Instrumentalists: Data Positivism since World War II. Historical Studies of the Natural Sciences. 48 (5), 673-684. (2018).

8. Private Equity Investment in Artificial Intelligence. OECD. December (2018). URL: private-equity-investment-in-artificial-intelligence.pdf

9. Artificial Intelligence Market Size, Industry Analysis Report, Regional Outlook, Application Development Potential, Price Trends, Competitive Market Share \& Forecast, 2019 - 2025. URL: https://www.gminsights.com/industryanalysis/artificial-intelligence-market.

10. White Paper on Measures to Prevent Karoshi i, etc. (Annual report for FY2016). (2017). Ministry of Health, Labour and Welfare. URL: https://fpcj.jp/wp/wpcontent/uploads/2017/11/8f513ff4e9662ac515de9e646f63d8b5.pdf. 
11. RPA
https:/home.kpmg/jp/en/home/insights/2016/05/robotic-process-automation.html 12. Robots in Japan: History, Industrial Uses and Security. URL: http://factsanddetails.com/Japan/cat26/sub163/item873.html

13. Hiroshi Fujiwara. Why Japan leads industrial robot production. URL: https://ifr.org/post/why-japan-leads-industrial-robot-production

[14] Yatao Zhong, Bicheng Xu, Guang-Tong Zhou, Luke Bornn, Greg Mori. Time Perception Machine: Temporal Point Processes for the When, Where and What of Activity Prediction. URL: https://arxiv.org/pdf/1808.04063.pdf

15. Sujeong Kim, Stephen J. Guy, Wenxi Liu, Rynson W. H. Lau, Ming C. Lin and Dinesh Manocha. Predicting Pedestrian Trajectories Using Velocity-Space Reasoning.

URL: https://www.researchgate.net/publication/265633089_Predicting_Pedestrian_Traje ctories_Using_Velocity-

Space_Reasoning/link/54ecdbfd0cf27fbfd771afa0/download.

16. L. Du, A. Maki. 'Minority Report' gets real as Japan startup develops AI cameras to spot shoplifters before they steal. URL: https://www.japantimes.co.jp/news/2019/03/05/business/tech/minority-report-getsreal-japan-startup-develops-ai-cameras-spot-shoplifters-steal/\#.XlhUa8AlJdg.

17. Japan plans 10 'AI hospitals' to ease doctor shortages. Computers will fill in patient records and analyze blood tests. Nikkei staff writers August 09, 2018. URL: https://asia.nikkei.com/Politics/Japan-plans-10-AI-hospitals-to-ease-doctorshortages

18. Why Artificial Intelligence Is The Key to Fixing Japan's Rigid Education System. URL: https://www.disruptingjapan.com/artificialintelligence-key-reforming-japans-rigid-eduction-system. 